\title{
Monetary Policy Capture and Political Stabilization
}

\author{
Francesco Salsano ${ }^{1,}$ \\ ${ }^{1}$ Dipartimento di Scienze Giuridiche "Cesare Beccaria", Università degli Studi di Milano, Italy \\ Correspondence: Dipartimento di Scienze Giuridiche "Cesare Beccaria", Università degli Studi di Milano, Via \\ Festa del Perdono 7, 20122 Milano Italy. E-mail: Francesco.salsano@ unimi.it
}

Received: November 17, 2019

Accepted: December 11, 2019 Online Published: December 15, 2019

doi:10.5539/ijef.v12n1p8

URL: https://doi.org/10.5539/ijef.v12n1p8

\begin{abstract}
The paper is an extension of the Gabillon and Martimort model (2004), which studies how the independence of the institution in charge of monetary policy may stabilize inflationary fluctuations due to political uncertainty when the economy is characterized by lobbies that seek to promote their own interests to the detriment of the general interests of society. This extension strengthens the hypothesis that the independence of the CB is the best institutional design with which to protect the general interests of 'society'. In fact, a Central Banker independent from the political principal that appoints it represents the best control by the minority with respect to decisions taken by the elected political majority.
\end{abstract}

Keywords: monetary policy, central bank, Partisan politics

\section{Introduction}

The question of the Central Bank, its political independence, its tasks, and how it fulfils them, has returned to the centre of political discussion. The Anglo-American subprime crisis of 2007 and the European sovereign debt crisis of 2011 generated intense pressure by politicians, financial institutions, employers and trade unions for a further extension of the competence of Central Banks in financial supervision, and for expansion of the objectives and degrees of freedom in the monetary policy that Central Banks implement.

This paper examines a case in which the Central Bank must pursue its objectives, while diverse actors, such as political institutions (government or parliament), financial institutions (commercial banks, investment funds, insurance companies) and in general all organized interest groups (lobbies) apply strong pressure on the Central Bank in order to 'capture' it and ensure monetary policy decisions which do not conflict with their interests (Note 1).

This is a problem common to all processes of delegation by a principal - the government, parliament or politicians in the broad sense - to an agent - the 'authority' or an independent bureaucrat.

The core question is this: what are the costs and benefits of granting independence to these regulatory authorities?

A body of economic literature (Stigler, 1971; Posner 1974; Laffont \& Tirole, 1993; Laffont \& Martimort, 1999; Faure-Grimaud \& Martimort, 2001) has sought to give an answer to this question by analysing the interactions among a regulatory agency, its political principals, and the interest group which is supposed to be regulated.

In the case of monetary policy, the conflict of interest among economic agents, which in turn reflects their diversity, is essential for interpretation of these costs and benefits.

The conflict of interest relates to the creditors/debtors issue in the economy. Inflation reduces the real weight of a non-indexed debt - i.e. one which remains fixed in nominal terms - while disinflation aggravates that weight. For debtors, inflation means lower real debt, whereas disinflation means higher debt. Thus generated is a symmetrical redistributive effect: inflation redistributes from creditors to debtors; disinflation does so from debtors to creditors. In a context of this kind, the banks and large financial groups (Note 2) are anti-inflation actors (Note 3). By contrast, small business owners and farmers, who have an incentive to favour 'surprise inflation' in order to pay lower real wages, or all economic actors exposed to the banking sector, are pro-inflation groups (Note 4).

To be noted is that interest groups (lobbies) have a particularly influential role only if they can corrupt and acquire particular economic information also available to the Central Banker: in this case the lobbies have an 
interest in inducing the monetary authority to conceal important information so that they can gain an advantage.

The institutional design of monetary policy - for example, the degree of independence of the Central Bank may also influence the relationship between interest groups and the monetary authority (Cukierman, 2013).

It can be also hypothesised that the more a Central Bank is independent of the government, the more vulnerable it will be to the pressure of interest groups.

All these aspects have been analysed by Gabillon and Martimort (2004), who consider a 'two-tier' model of monetary policy where the Central Banker is subject to both explicit influence by the elected political principal through a contract and implicit influence by anti-inflation interest groups seeking to 'capture' monetary policy. The degree of political independence therefore influences the agency costs paid to control the Central Banker. The result obtained by Gabillon and Martimort (2004) is that political independence increases the agency costs (agency cost effects) but prevents greater fluctuations in inflation due to exogenous political uncertainty with respect to the election result (stabilization effect). On comparing the two effects, ex-ante social welfare increases in the case of political independence.

This paper investigates how the independence of the Central Bank influences the election outcome when political uncertainty is endogenized in Gabillon and Martimort's model, considering forward-looking voters who make their decisions by comparing the policy platforms proposed by the two main political competitors.

The rest of the paper is organized as follows. Section 2 presents a summary of Gabillon and Martimort's model; Section 3 describes our extension of this model; finally, Section 4 sets out the conclusions.

\section{The Gabillon-Martimort Model}

Gabillon and Martimort (2004) provide an explanation for a possible link between the degree of independence of a Central Bank (CB) and policy stabilization. The first key ingredient of the model is the possibility of capture of these agencies by the interest groups in the financial sector. Indeed, in a world of information asymmetries, regulators accumulate information about the welfare effects of different policies and they can be bribed to manipulate information. The second ingredient is political uncertainty. The extent to which a Central Bank is affiliated to a political party affects the likelihood that this particular agency remains in place as political powers alternate in office. The status of the Central Bank thus significantly changes the collusive opportunities between this Central Bank and the financial industry.

In this section, we summarize the main elements of the Gabillon-Martimort model (Note 5). This will serve the purposes of the next section, in which we proceed with extension of this model.

Contrary to the literature on monetary institutions that takes the contractual approach, the CB's incentive mechanisms are not designed by a social planner, but by partisan political principals (Note 6) who want to please different constituencies and thus express different concerns for the trade-off between price control and surprise inflation depending on whether they represent a leftist or a rightist constituency (Note 7). Because of information asymmetry between the $\mathrm{CB}$ and the government, there is also scope for collusion between private interest groups and the $\mathrm{CB}$. However, the scope for capture depends on the exact control rights that principals retain over the CB.

\subsection{Preferences}

$\boldsymbol{C B}$ : The CB receives a monetary transfer $s$ from whichever political principal has been elected to perform the monetary policy. The CB's utility is $\mathrm{V}=\mathrm{s}$.

This transfer can be viewed as the share of the central bank budget and resources that can be diverted by the monetary authority for its private use. Alternatively it can also be interpreted as the probability of being promoted to a higher position in the civil service times the benefits of this higher position.

Political Principals: A political principal maximises an objective function à la Barro-Gordon (1983):

$$
S W_{\alpha i}=-\pi^{2} / 2+\alpha_{i} \theta\left(\pi-\pi^{e}\right)-S
$$

where $\pi$ is the inflation level, $\pi^{e}$ its expectations, $\alpha_{i}>0$ (with $i \in\{L, R\}$ ) is the weight that the political principal gives to creating surprise inflation. $\theta$ is a macroeconomic shock affecting both political principals' concerns for output expansion. $s$ is the transfer given to the CB (Note 8).

A rightist government is less willing to create surprise inflation than a leftist one. $\Delta \alpha=\alpha_{L}-\alpha_{R}>0$ represents the degree of polarization of the society i.e. the difference between the concerns for surprise inflation between a 
leftist party and a rightist one. The probabilities of each of these two political principals being elected are exogenous $\left(\alpha=\alpha_{R}\right.$ with probability $p$ and $\alpha=\alpha_{L}$ with probability $\left.1-p\right)$. In the next section we will change this assumption.

Interest group: The anti-inflationist group obtains a utility from unexpected inflation which is equal to: $I G=-\beta \theta\left(\pi-\pi^{e}\right)$ with $\beta>0$ (Note 9).

\subsection{Information structure}

The shock is $\theta$ drawn from a common knowledge distribution on $\Theta=\{\bar{\theta}, \underline{\theta}\}$ with respective probabilities 1 - v and v. It is possible to normalise $\bar{\theta}=1$ so that we have $\Delta \theta=1-\theta>0$. Anti-inflationist incentives are thus greater when $\underline{\theta}$ is realised. The $\mathrm{CB}$ and the interest group have complete information on the shock $\theta$. This information structure has already been discussed in the literature by Peek, Rosemgren, and Tootell (1999), who analyze the relationship between monetary policy and problems in the banking sector, which may serve as an early indicator of deteriorating macroeconomic conditions.

Instead, at the time when the CB's incentives are designed, the political principals and the (non-financial) private sector remain uninformed about the exact value of this shock.

The CB can conceal verifiable evidence that the economy is doing badly $(\theta)$ and instead announce that $\hat{\theta}=\underline{\theta}$. The mere possibility that the $\mathrm{CB}$ can conceal such information is the 'key' to understanding the scope for collusion with an anti-inflationist interest group. Conversely, the CB can issue credible reports about the real state of the economy (Note 10).

\subsection{Incentive Contract}

Study of the properties of mechanisms designed to prevent collusion between several members of an organization has become a highly active area of research since the pioneering work of Tirole (1986).

When, as in our case, a supervisor (CB) and an agent (Financial Sector) have complete information about an event (the real situation of the economy), while a principal (Political Principal) is not informed about this event, we can verify that agent-supervisor coalitions can be formed to maximize private objectives and potentially defeat the purpose for which that supervision has been established. Our analysis will now take account of the possibility that such collusive behaviour of the agent and the supervisor may occur. We can assume that the two parties agree by way of a side-contract. This side-contract will reduce the ability of the principal to extract information from the supervisor. To avoid such collusion, the principal can in turn reward the supervisor for every report on the true state of the economy.

The optimal contract is always the contract that deters collusion. Should collusion occur, at the optimum the principal can always alter the contract by making quantity transfers independent of the supervisor's report, and collusion will be deterred because it is no longer useful to the agent. This is known as the collusion-proofness principle.

Hence, to deter collusion, the principal must be sure to reward the supervisor for reporting the truth by an amount that is exactly equal to the maximum bribe that the agent can offer the supervisor to keep quiet: anything less will open the door to collusion, and anything more will be a waste of money.

\subsection{CB contracts and Collusion Technology}

The grand-contract between the elected political principal and the CB consists of wages s and inflation targets $\pi$.

$\left(\underline{s}_{i}, \underline{\pi}_{i}\right)$ (resp. $\left(\bar{s}_{i}, \bar{\pi}_{i}\right)$ ) represents, respectively, the wage and inflation target when the economy is going well

\section{$\underline{\theta}$ (resp. goes badly, $\bar{\theta}$ ).}

The side-contract or collusion between the CB and the interest group consists of secret side-transfers. The CB has all the bargaining power in the design of side-contracts. When the economy is going badly, the anti-inflationist interest groups want the CB to report $\underline{\theta}$ to keep inflation low. From the false report of the CB to the political principal, the interest group earns:

$$
\beta \bar{\theta}\left[\left(\bar{\pi}_{i}-\pi_{i}^{e}\right)-\left(\underline{\pi}_{i}-\pi_{i}^{e}\right)\right]=\beta \Delta \pi_{i} .
$$


The interest group is not willing to bribe the CB to misreport when $\underline{\theta}$ realizes, since doing so would increase inflation. However, because of the illegal nature of capture, the side-contract between this group and the $\mathrm{CB}$ suffers from some transaction costs (Note 11). The exchange of $\tau$ units of bribes only yields the CB a private benefit from holding office: $K(\tau)=k \tau-\frac{r}{2} \tau^{2}$, where $0<k \leq 1$ and $\mathrm{r}>0$, so that the transaction costs of side-contracting are equal: $\tau-\mathrm{K}(\tau)$ (Note 12$)$.

\subsection{The Legal Status of the $C B$}

The CB has political independence (PI) when he cannot be fired by the newly-elected political principal. Under political control (PC) the CB is in power if the party with which he is affiliated is elected. In this case, the principal has control rights on who should be the head of the Central Bank.

\subsection{Timings}

The timing of the game depends on the legal status of the Central Bank.

Under political control it is as follows:

$\mathrm{T}=0$ : The electoral outcome realizes, and the preferences of the elected political principal are known to all players including the private sector of the economy.

$\mathrm{T}=1$ : The $\mathrm{CB}$ receives a grand-contract from the political principal that has just been elected. This contract stipulates wages and inflation targets. The private sector forms its expectations on inflation and negotiates wage contracts.

$\mathrm{T}=2$ : Ex-post collusion stage. If the $\mathrm{CB}$ has accepted the grand-contract, he offers a side-contract to the interest group. This side-contract consists of a bribe in exchange for hiding the item of information that he has available. This side-contract is accepted or rejected.

$\mathrm{T}=3: \theta$ is learned by the $\mathrm{CB}$ and the interest group.

$\mathrm{T}=4$ : The CB makes an announcement on the state of the economy, and the corresponding inflation target and wage are implemented. Side-transfers, if any, are exchanged.

Importantly, under political control the $\mathrm{CB}$ and the interest group cannot agree on a side-contract before political uncertainty is resolved. Instead, an independent $\mathrm{CB}$ and the interest group can also agree on an ex-ante side-contract.

With an independent $\mathrm{CB}$, the timing of the game is in part as above:

$\mathrm{T}=0$ : Both political parties propose their electoral platforms non-cooperatively. These platforms consist of incentive contracts to the CB. These grand-contracts stipulate budgets and inflation targets conditionally on whether the offering party is elected. The $\mathrm{CB}$ accepts or rejects both grand-contracts, being still uninformed on the state of the economy $\theta$.

$\mathrm{T}=1$ : Ex-ante collusion stage. If the CB has accepted the grand-contracts, he offers a side-contract to the interest group. This side-contract is now conditional on the electoral outcome.

$\mathrm{T}=2$ : The electoral outcome realizes and the preferences of the political principal are known to all players including the private sector of the economy, which now forms its expectations on inflation.

Stages $\mathrm{T}=3$ and $\mathrm{T}=4$ are then the same as with affiliated CBs.

\subsection{A Benchmark wth Complete Information}

Under complete information, the first best inflation targets, $\underline{\pi}_{i}$ and $\bar{\pi}_{i}$, offered by the elected political principal i maximize expected welfare defined as:

s.t. $\pi_{i}^{e}=v \underline{\pi}_{i}+(1-v) \bar{\pi}_{i}$.

$$
\operatorname{Max}_{\left.\underline{\underline{\pi_{i}}}, \bar{\pi}_{i}\right)} v\left[-\frac{\underline{\pi}_{i}^{2}}{2}+\underline{\theta} \alpha_{i}\left(\underline{\pi}_{i}-\pi_{i}^{e}\right)\right]+(1-v)\left[-\frac{\bar{\pi}_{i}^{2}}{2}+\alpha_{i}\left(\bar{\pi}_{i}-\pi_{i}^{e}\right)\right]
$$

Rewriting the principal's objective as a function of average inflation $\pi_{i}^{e}$ and the difference in inflation targets $\Delta \pi_{i}=\bar{\pi}_{i}-\underline{\pi}$ the principal's problem becomes: 


$$
\underset{\left(\pi_{i}^{e}, \Delta \pi_{i}\right)}{\operatorname{Max}}-\frac{\left(\pi_{i}^{e}\right)^{2}}{2}+v(1-v)\left(\alpha_{i} \Delta \theta \Delta \pi_{i}-\frac{\left(\Delta \pi_{i}\right)^{2}}{2}\right) .
$$

In the case of full commitment to a policy rule, the optimal monetary policy requires:

$$
\pi_{i}^{F B e}=0
$$

The difference in inflation targets between both states of the world is thus:

$$
\Delta \pi_{i}^{F B}=\alpha_{i} \Delta \theta>0
$$

The above commitment policy has been extensively criticized for not being time-consistent. Gabillon and Martimort investigate instead how this policy is robust to political pressures. Taking this perspective highlights that different institutional designs offer different responses to agency problems. They find that: $\Delta \pi_{R}^{P C}<\Delta \pi_{R}^{P I}<\Delta \pi_{L}^{P I}<\Delta \pi_{L}^{P C}$ (Note 13). However, granting political independence to the CB somewhat insulates monetary policy from political fluctuations: a stabilization effect. The cost of independence is nevertheless that the $\mathrm{CB}$ is more prone to capture by interest groups: a delegation effect. The stabilization effect is always strong enough to dominate the delegation effect. Hence, ex ante social welfare is greater under political independence than under political control.

\section{An Extension of Gabillon-Martimort's Model with Endogenous Political Uncertainty}

In this section, election probabilities are thus endogenized, with each party's probability of success depending on both its own and the other parties' policies. This approach (Note 14) considerably revises the properties of the classic partisan model. Most notably, we demonstrate that endogenous voting will have important consequences for the magnitude of the partisan effect.

Let us now endogenize political uncertainty in Gabillon-Martimort's model by assuming that forward-looking voters decide their ballot by comparing the expected payoffs that they will obtain with each party. Voters are ideologically differentiated with respect to the trade-off that they would implement between surprise inflation and price stabilization i.e. with respect to their $\alpha$ (Note 15). This parameter may in this case be interpreted as representing the voter's location in the wealth distribution.

\subsection{Monetary Policy under Political Control}

Let us first consider the case when the Central Banker is under political control. Because agent $\alpha$ is indifferent between a rightist policy $\Delta \pi_{R}$ and a leftist policy implementing $\Delta \pi_{L}$, it must obtain the same expected payoff with both policies. Hence:

$$
S W_{\alpha}\left(\Delta \pi_{R}\right)=S W_{\alpha}\left(\Delta \pi_{L}\right)
$$

Following Gabillon and Martimort (2004), we now write social welfare, in regime political control with party $i \in\{L, R\}$, under asymmetric information and the threat of capture, thus:

$$
S W\left(\Delta \pi_{i}\right)=-\frac{\left(\pi_{i}^{e}\right)^{2}}{2}+v(1-v)\left(\alpha_{i} \Delta \theta \Delta \pi_{i}-\frac{\left(\Delta \pi_{i}\right)^{2}}{2}\right)-A C_{i}^{P C}\left(\Delta \pi_{i}\right) \quad \text { (Note 16) }
$$

where $A C_{i}^{P C}\left(\Delta \pi_{i}\right)=(1-v) K\left(\beta \Delta \pi_{i}\right)$ is the agency cost associated with the delegation of monetary policy to the CB (Note 17).

Under asymmetric information and political control, the optimal collusion-proof monetary policy offered by a political principal i entails no inflationary bias, so that:

$$
\pi_{i}^{e}=0
$$

We now rewrite the social welfare function as follows:

$$
S W\left(\Delta \pi_{i}\right)=v\left(\alpha_{i} \Delta \theta \Delta \pi_{i}-\frac{\left(\Delta \pi_{i}\right)^{2}}{2}\right)-\left[k \beta \Delta \pi_{i}-\frac{r}{2}\left(\beta \Delta \pi_{i}\right)^{2}\right]
$$


The probability of the political party $\mathrm{i}$ (with $\mathrm{i}=$ Right, Left) being elected is a function of politically induced fluctuations in the variance of inflation, thus: $P=p\left(\Delta \pi_{L}-\Delta \pi_{R}\right)$.

We take from Friedman the hypothesis of variance of inflation. Indeed, Friedman (1977) considered why policy makers may be affected by inflation variability. Friedman wanted to explain why there is a positive correlation between the level of inflation and the variability of inflation across countries and over time for any given country. In Friedman's analysis, a government may temporarily pursue a set of policy goals (output, employment) that lead to high inflation; this, in turn, elicits strong political pressure to reduce the debasing of the currency. Chowdhury (1991) re-examined the relation between the level and the variability of inflation for a sample of sixty-six countries over the 1955-90 period. His results indicate the presence of a significant positive relation between the rate of inflation and its variability.

In a Nash equilibrium of the choice of the political right-wing party platforms, $Z_{R}$ chooses $\Delta \pi_{R}$ so that it maximizes:

$$
p\left(\Delta \pi_{L}-\Delta \pi_{R}\right) S W_{\alpha R}\left(\Delta \pi_{R}\right)+\left[1-p\left(\Delta \pi_{L}-\Delta \pi_{R}\right)\right] S W_{\alpha_{R}}\left(\Delta \pi_{L}\right)
$$

Then:

$$
\begin{aligned}
& p\left(\Delta \pi_{L}-\Delta \pi_{R}\right)\left\{v\left(\alpha_{R} \Delta \theta \Delta \pi_{R}-\frac{\left(\Delta \pi_{R}\right)^{2}}{2}\right)-\left[k \beta\left(\Delta \pi_{R}\right)-\frac{r}{2}\left(\beta \Delta \pi_{R}\right)^{2}\right]\right\}+ \\
& +\left[1-p\left(\Delta \pi_{L}-\Delta \pi_{R}\right)\right]\left\{v\left(\alpha_{R} \Delta \theta \Delta \pi_{L}-\frac{\left(\Delta \pi_{L}\right)^{2}}{2}\right)-\left[k \beta\left(\Delta \pi_{L}\right)-\frac{r}{2}\left(\beta \Delta \pi_{L}\right)^{2}\right]\right\}
\end{aligned}
$$

$Z_{R}$ now takes into account the impact of its policy choice on the probability of being elected. The corresponding first-order condition (FOC) is now written as:

$$
\begin{aligned}
& p\left(\Delta \pi_{L}-\Delta \pi_{R}\right)\left\{v\left(\alpha_{R} \Delta \theta-\Delta \pi_{R}\right)-k \beta+r \beta^{2} \Delta \pi_{R}\right\}+ \\
& -p^{\prime}\left(\Delta \pi_{L}-\Delta \pi_{R}\right)\left\{v\left(\alpha_{R} \Delta \theta \Delta \pi_{R}-\frac{\left(\Delta \pi_{R}\right)^{2}}{2}\right)-\left[k \beta\left(\Delta \pi_{R}\right)-\frac{r}{2}\left(\beta \Delta \pi_{R}\right)^{2}\right]\right\} \\
& +p^{\prime}\left(\Delta \pi_{L}-\Delta \pi_{R}\right)\left\{v\left(\alpha_{R} \Delta \theta \Delta \pi_{L}-\frac{\left(\Delta \pi_{L}\right)^{2}}{2}\right)-\left[k \beta\left(\Delta \pi_{L}\right)-\frac{r}{2}\left(\beta \Delta \pi_{L}\right)^{2}\right]\right\}=0
\end{aligned}
$$

After some algebra we obtain:

$$
\begin{aligned}
& \Delta \pi_{R}^{P C}=\frac{\alpha_{R} \Delta \theta-\frac{K \beta}{v}}{1-\frac{r \beta^{2}}{v}}+ \\
& +\frac{\underbrace{\prime}\left(\Delta \pi_{L}-\Delta \pi_{R}\right)}{p\left(\Delta \pi_{L}-\Delta \pi_{R}\right)}\left\{\frac{\alpha_{R} \Delta \theta-\frac{K \beta}{v}}{1-\frac{r \beta^{2}}{v}}\left(\Delta \pi_{L}-\Delta \pi_{R}\right)-\frac{1}{2}\left[\left(\Delta \pi_{L}\right)^{2}-\left(\Delta \pi_{R}\right)^{2}\right]\right\}
\end{aligned}
$$

In the case of the left, $Z_{L}$ chooses $\Delta \pi_{L}$ so that it maximizes:

$$
p\left(\Delta \pi_{L}-\Delta \pi_{R}\right) S W_{\alpha_{L}}\left(\Delta \pi_{R}\right)+\left[1-p\left(\Delta \pi_{L}-\Delta \pi_{R}\right)\right] S W_{\alpha_{L}}\left(\Delta \pi_{L}\right)
$$

Then:

$$
\begin{aligned}
& p\left(\Delta \pi_{L}-\Delta \pi_{R}\right)\left\{v\left(\alpha_{L} \Delta \theta \Delta \pi_{R}-\frac{\left(\Delta \pi_{R}\right)^{2}}{2}\right)-\left[k \beta\left(\Delta \pi_{R}\right)-\frac{r}{2}\left(\beta \Delta \pi_{R}\right)^{2}\right]\right\}+ \\
& +\left[1-p\left(\Delta \pi_{L}-\Delta \pi_{R}\right)\right]\left\{v\left(\alpha_{L} \Delta \theta \Delta \pi_{L}-\frac{\left(\Delta \pi_{L}\right)^{2}}{2}\right)-\left[k \beta\left(\Delta \pi_{L}\right)-\frac{r}{2}\left(\beta \Delta \pi_{L}\right)^{2}\right]\right\}
\end{aligned}
$$

The corresponding FOC is now written as: 


$$
\begin{aligned}
& p^{\prime}\left(\Delta \pi_{L}-\Delta \pi_{R}\right)\left\{v\left(\alpha_{L} \Delta \theta \Delta \pi_{R}-\frac{\left(\Delta \pi_{R}\right)^{2}}{2}\right)-\left[k \beta\left(\Delta \pi_{R}\right)-\frac{r}{2}\left(\beta \Delta \pi_{R}\right)^{2}\right]\right\}+ \\
& +\left[1-p\left(\Delta \pi_{L}-\Delta \pi_{R}\right)\right]\left\{v\left(\alpha_{L} \Delta \theta-\Delta \pi_{L}\right)-\left[k \beta-r \beta^{2} \Delta \pi_{L}\right]\right\}+ \\
& -p^{\prime}\left(\Delta \pi_{L}-\Delta \pi_{R}\right)\left\{v\left(\alpha_{L} \Delta \theta \Delta \pi_{L}-\frac{\left(\Delta \pi_{L}\right)^{2}}{2}\right)-\left[k \beta\left(\Delta \pi_{L}\right)-\frac{r}{2}\left(\beta \Delta \pi_{L}\right)^{2}\right]\right\}=0
\end{aligned}
$$

It follows that:

$$
\begin{aligned}
& \Delta \pi_{L}^{P C}= \\
& =\frac{\alpha_{L} \Delta \theta-\frac{K \beta}{v}}{1-\frac{r \beta^{2}}{v}}-\underbrace{\frac{p^{\prime}\left(\Delta \pi_{L}-\Delta \pi_{R}\right)}{1-p\left(\Delta \pi_{L}-\Delta \pi_{R}\right)}\left\{\frac{\alpha_{L} \Delta \theta-\frac{K \beta}{v}}{1-\frac{r \beta^{2}}{v}}\left(\Delta \pi_{L}-\Delta \pi_{R}\right)-\frac{1}{2}\left[\left(\Delta \pi_{L}\right)^{2}-\left(\Delta \pi_{R}\right)^{2}\right]\right\}}_{\text {Electoral effect }}
\end{aligned}
$$

(6) and (9) represent a system of nonlinear differential equations. We solve this system numerically. The results of the simulations are shown in figures (1) (2) (3) and (4) for different values of some parameters.

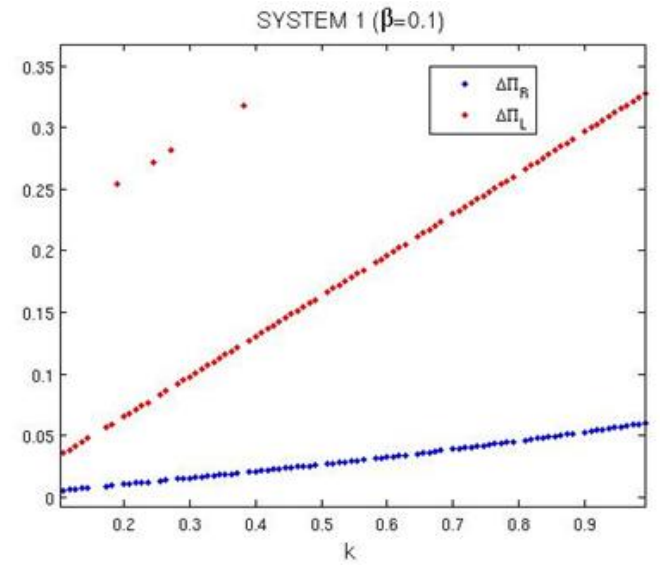

Figure 1.

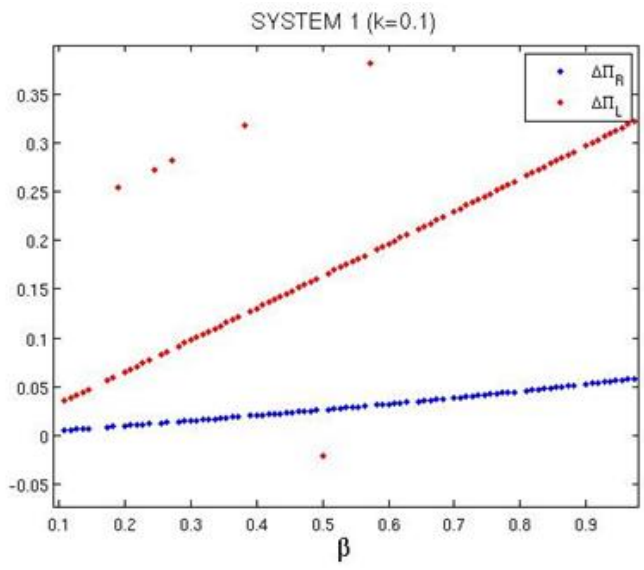

Figure 3.

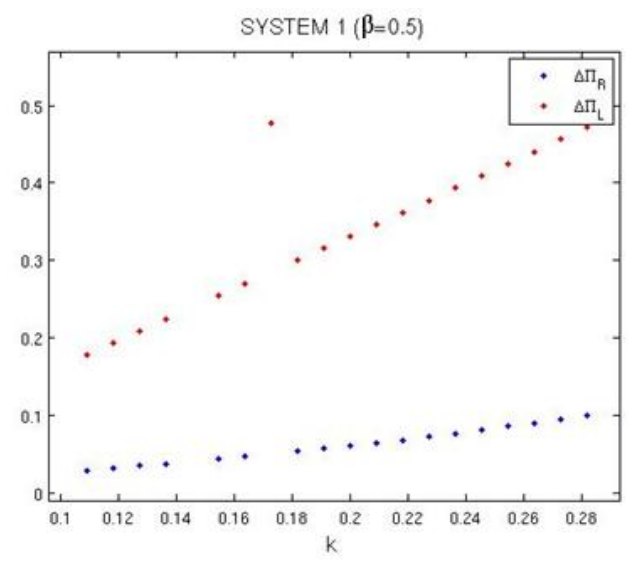

Figure 1.

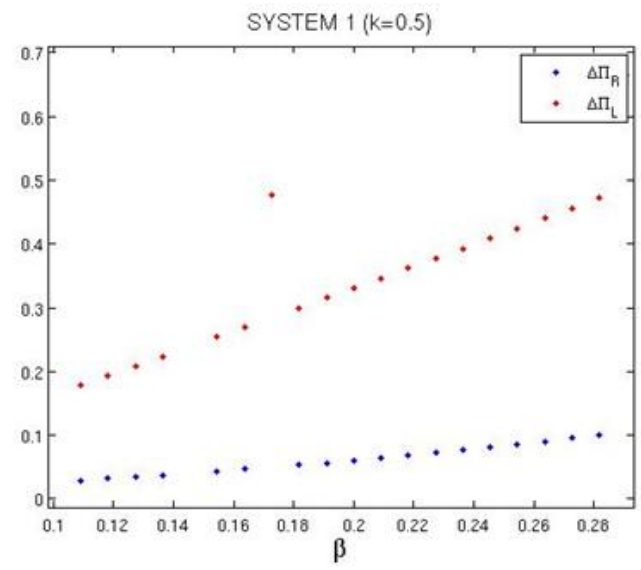

Figure 4.

Direct observations show that the electoral effect is negative with the left and positive with the right (Note 18). Indeed, reducing (resp. increasing) the difference in inflation targets now increases the probability that the left (resp. right) is elected and, for this reason, the left offers a platform shifted downwards.

\subsection{Monetary Policy under Political Independence}

Under the political independence of the Central Banker, monetary policy is carried out for both political 
principals. For this reason, the Central Banker can offer a side-contract to the anti-inflationist interest group before political uncertainty is resolved (Note 19).

Therefore, with political independence, the agency cost associated with the delegation of monetary policy to the $\mathrm{CB}$ is written thus in the case of a rightist government:

$$
A C_{R}^{P I}\left(\Delta \pi_{R}\right)=\frac{1}{p}(1-v)\left[K\left(\beta\left(p \Delta \pi_{R}+(1-p) \Delta \pi_{L}\right)\right)-(1-p)\left(\bar{s}_{L}-\underline{s}_{L}\right)\right]
$$

in the case of a leftist government:

$$
A C_{L}^{P I}\left(\Delta \pi_{L}\right)=\frac{1}{1-p}(1-v)\left[K\left(\beta\left(p \Delta \pi_{R}+(1-p) \Delta \pi_{L}\right)\right)-p\left(\bar{s}_{R}-\underline{s}_{R}\right)\right]
$$

Because agent $\alpha$ is indifferent between a rightist policy $\Delta \pi_{R}$ and a leftist policy implementing $\Delta \pi_{L}$, it must obtain the same payoff with both policies. To simplify, we focus on the case where both parties pay the same wage to the independent Central Banker in an interior equilibrium, i.e., we posit a particular distribution of the gains from dealing with a common bureaucrat.

The identity of the swing voter $\alpha$ is now such that:

$$
S W_{\alpha}\left(\Delta \pi_{R}\right)+(1-v) K\left(\beta \Delta \pi_{R}\right)=S W_{\alpha}\left(\Delta \pi_{L}\right)+(1-v) K\left(\beta \Delta \pi_{L}\right)
$$

In a Nash equilibrium, $Z_{R}$ chooses $\Delta \pi_{R}$ so that it maximizes:

$$
\begin{aligned}
& p\left(\Delta \pi_{L}-\Delta \pi_{R}\right) S W_{\alpha R}\left(\Delta \pi_{R}\right)+\left[1-p\left(\Delta \pi_{L}-\Delta \pi_{R}\right)\right] S W_{\alpha R}\left(\Delta \pi_{L}\right)+(1-v)\left[p\left(\Delta \pi_{L}-\Delta \pi_{R}\right) k\left(\beta \Delta \pi_{R}\right)\right]+ \\
& \left.+(1-v)\left\{1-p\left(\Delta \pi_{L}-\Delta \pi_{R}\right)\right] k\left(\beta \Delta \pi_{L}\right)\right\}-(1-v) k\left[\beta\left(p \Delta \pi_{R}+(1-p) \Delta \pi_{L}\right)\right]
\end{aligned}
$$

and then follows:

$$
\begin{aligned}
& p\left(\Delta \pi_{L}-\Delta \pi_{R}\right)\left\{v\left(\alpha_{R} \Delta \theta \Delta \pi_{R}-\frac{\left(\Delta \pi_{R}\right)^{2}}{2}\right)-\left[k \beta\left(\Delta \pi_{R}\right)-\frac{r}{2}\left(\beta \Delta \pi_{R}\right)^{2}\right]\right\}+ \\
& +\left[1-p\left(\Delta \pi_{L}-\Delta \pi_{R}\right)\right]\left\{v\left(\alpha_{R} \Delta \theta \Delta \pi_{L}-\frac{\left(\Delta \pi_{L}\right)^{2}}{2}\right)-\left[k \beta\left(\Delta \pi_{L}\right)-\frac{r}{2}\left(\beta \Delta \pi_{L}\right)^{2}\right]\right\}+ \\
& +(1-v)\left\{p\left(\Delta \pi_{L}-\Delta \pi_{R}\right)\left[k\left(\beta \Delta \pi_{R}\right)-\frac{r \beta^{2}}{2}\left(\Delta \pi_{R}\right)^{2}\right]\right\}+ \\
& +(1-v)\left\{\left[1-p\left(\Delta \pi_{L}-\Delta \pi_{R}\right)\right]\left[k\left(\beta \Delta \pi_{L}\right)-r \beta^{2} \frac{\left(\Delta \pi_{L}\right)^{2}}{2}\right]\right\}+ \\
& -(1-v)\left\{k \beta\left[\left(p \Delta \pi_{R}+(1-p) \Delta \pi_{L}\right)\right]-\frac{r \beta^{2}}{2}\left[p \Delta \pi_{R}+(1-p) \Delta \pi_{l}\right]^{2}\right\}
\end{aligned}
$$

The corresponding FOC becomes:

$$
\begin{aligned}
& p\left(\Delta \pi_{L}-\Delta \pi_{R}\right)\left\{v\left(\alpha_{R} \Delta \theta-\Delta \pi_{R}\right)-k \beta+r \beta^{2} \Delta \pi_{R}\right\}+ \\
& -p^{\prime}\left(\Delta \pi_{L}-\Delta \pi_{R}\right)\left\{v\left(\alpha_{R} \Delta \theta \Delta \pi_{R}-\frac{\left(\Delta \pi_{R}\right)^{2}}{2}\right)-\left[k \beta\left(\Delta \pi_{R}\right)-\frac{r}{2}\left(\beta \Delta \pi_{R}\right)^{2}\right]\right\}+ \\
& +p^{\prime}\left(\Delta \pi_{L}-\Delta \pi_{R}\right)\left\{v\left(\alpha_{R} \Delta \theta \Delta \pi_{L}-\frac{\left(\Delta \pi_{L}\right)^{2}}{2}\right)-\left[k \beta\left(\Delta \pi_{L}\right)-\frac{r}{2}\left(\beta \Delta \pi_{L}\right)^{2}\right]\right\}+ \\
& +(1-v)\left\{p\left(\Delta \pi_{L}-\Delta \pi_{R}\right)\left[k \beta-r \beta^{2}\left(\Delta \pi_{R}\right)\right]\right\}+ \\
& +(1-v)\left\{\left[-p^{\prime}\left(\Delta \pi_{L}-\Delta \pi_{R}\right)\right]\left[k\left(\beta \Delta \pi_{R}\right)-r \beta^{2} \frac{\left(\Delta \pi_{R}\right)^{2}}{2}\right]\right\}+ \\
& +(1-v)\left\{\left[p^{\prime}\left(\Delta \pi_{L}-\Delta \pi_{R}\right)\right]\left[k\left(\beta \Delta \pi_{L}\right)-r \beta^{2} \frac{\left(\Delta \pi_{L}\right)^{2}}{2}\right]\right\}+ \\
& \left.-(1-v)\left\{k \beta\left[p-p^{\prime} \Delta \pi_{R}+p^{\prime} \Delta \pi_{L}\right]-r \beta^{2}\left[p \Delta \pi_{R}+(1-p) \Delta \pi_{L}\right]\right]\left[p-p^{\prime} \Delta \pi_{R}+p^{\prime} \Delta \pi_{L}\right]\right\}=0
\end{aligned}
$$

After some algebra we obtain: 


$$
\left.\begin{array}{l}
\Delta \pi_{R}^{P I}=\frac{\alpha_{R} \Delta \theta-\frac{k \beta}{v}}{1-r \beta^{2}}+ \\
\left.+\frac{p^{\prime}\left(\Delta \pi_{L}-\Delta \pi_{R}\right)}{p\left(\Delta \pi_{L}-\Delta \pi_{R}\right)}\left\{\frac{\alpha_{R} \Delta \theta-k \beta}{1-r \beta^{2}}\left(\Delta \pi_{L}-\Delta \pi_{R}\right)-\frac{1}{2}\left[\left(\Delta \pi_{L}\right)^{2}-\left(\Delta \pi_{R}\right)^{2}\right]\right\}+\right\} \\
-\frac{(1-v)}{v\left(1-r \beta^{2}\right)} \cdot \frac{1}{p\left(\Delta \pi_{L}-\Delta \pi_{R}\right)} \cdot\left\{k \beta p^{\prime}\left(\Delta \pi_{L}-\Delta \pi_{R}\right)-r \beta^{2}\left[p \Delta \pi_{R}+\right.\right. \\
\left.\left.+(1-p)\left(\Delta \pi_{L}\right)\right]\left(p-p^{\prime} \Delta \pi_{R}+p^{\prime} \Delta \pi_{L}\right)\right\}
\end{array}\right\} \text { Electoral effect }
$$

In a Nash equilibrium, $Z_{L}$ chooses $\Delta \pi_{L}$ so that it maximizes:

$$
\begin{aligned}
& p\left(\Delta \pi_{L}-\Delta \pi_{R}\right) S W_{\alpha L}\left(\Delta \pi_{R}\right)+\left[1-p\left(\Delta \pi_{L}-\Delta \pi_{R}\right)\right] S W_{\alpha L}\left(\Delta \pi_{L}\right)+(1-v)\left[p\left(\Delta \pi_{L}-\Delta \pi_{R}\right) k\left(\beta \Delta \pi_{R}\right)\right]+ \\
& (1-v)\left\{\left[1-p\left(\Delta \pi_{L}-\Delta \pi_{R}\right)\right] k\left(\beta \Delta \pi_{L}\right)\right\}-(1-v) k\left[\beta\left(p \Delta \pi_{R}+(1-p) \Delta \pi_{L}\right)\right]
\end{aligned}
$$

and then follows:

$$
\begin{aligned}
& p\left(\Delta \pi_{L}-\Delta \pi_{R}\right)\left\{v\left(\alpha_{L} \Delta \theta \Delta \pi_{R}-\frac{\left(\Delta \pi_{R}\right)^{2}}{2}\right)-\left[k \beta\left(\Delta \pi_{R}\right)-\frac{r}{2}\left(\beta \Delta \pi_{R}\right)^{2}\right]\right\}+ \\
& +\left[1-p\left(\Delta \pi_{L}-\Delta \pi_{R}\right)\right]\left\{v\left(\alpha_{L} \Delta \theta \Delta \pi_{L}-\frac{\left(\Delta \pi_{L}\right)^{2}}{2}\right)-\left[k \beta\left(\Delta \pi_{L}\right)-\frac{r}{2}\left(\beta \Delta \pi_{L}\right)^{2}\right]\right\}+ \\
& +(1-v)\left\{p\left(\Delta \pi_{L}-\Delta \pi_{R}\right)\left[k\left(\beta \Delta \pi_{R}\right)-\frac{r \beta^{2}}{2}\left(\Delta \pi_{R}\right)^{2}\right]\right\}+ \\
& +(1-v)\left\{\left[1-p\left(\Delta \pi_{L}-\Delta \pi_{R}\right)\right]\left[k\left(\beta \Delta \pi_{L}\right)-r \beta^{2} \frac{\left(\Delta \pi_{L}\right)^{2}}{2}\right]\right\}+ \\
& -(1-v)\left\{k\left[\beta\left(p \Delta \pi_{R}+(1-p) \Delta \pi_{L}\right)\right]-\frac{r \beta^{2}}{2}\left[p \Delta \pi_{R}+(1-p) \Delta \pi_{l}\right]^{2}\right\}
\end{aligned}
$$

The corresponding FOC becomes:

$$
\begin{aligned}
& p^{\prime}\left(\Delta \pi_{L}-\Delta \pi_{R}\right)\left\{v\left(\alpha_{L} \Delta \theta \Delta \pi_{R}-\frac{\left(\Delta \pi_{R}\right)^{2}}{2}\right)-\left[k \beta\left(\Delta \pi_{R}\right)-\frac{r}{2}\left(\beta \Delta \pi_{R}\right)^{2}\right]\right\}+ \\
& +\left[1-p\left(\Delta \pi_{L}-\Delta \pi_{R}\right)\right]\left\{v\left(\alpha_{L} \Delta \theta-\Delta \pi_{L}\right)-\left[k \beta-r \beta^{2} \Delta \pi_{L}\right]\right\}+ \\
& -p^{\prime}\left(\Delta \pi_{L}-\Delta \pi_{R}\right)\left\{v\left(\alpha_{L} \Delta \theta \Delta \pi_{L}-\frac{\left(\Delta \pi_{L}\right)^{2}}{2}\right)-\left[k \beta\left(\Delta \pi_{L}\right)-\frac{r}{2}\left(\beta \Delta \pi_{L}\right)^{2}\right]\right\}+ \\
& +(1-v)\left\{p^{\prime}\left(\Delta \pi_{L}-\Delta \pi_{R}\right)\left[k\left(\beta \Delta \pi_{R}\right)-\frac{r \beta^{2}}{2}\left(\Delta \pi_{R}\right)^{2}\right]\right\}+ \\
& +(1-v)\left\{\left[1-p\left(\Delta \pi_{L}-\Delta \pi_{R}\right)\right]\left[k \beta-r \beta^{2}\left(\Delta \pi_{L}\right)\right]\right\} \\
& -(1-v)\left\{\left[p^{\prime}\left(\Delta \pi_{L}-\Delta \pi_{R}\right)\right]\left[k\left(\beta \Delta \pi_{L}\right)-r \beta^{2} \frac{\left(\Delta \pi_{L}\right)^{2}}{2}\right]\right\}-(1-v) \\
& \left\{k\left[\beta\left(p^{\prime} \Delta \pi_{R}+(1-p)-p^{\prime} \Delta \pi_{L}\right)\right]-r \beta^{2}\left[p \Delta \pi_{R}+(1-p) \Delta \pi_{L}\right]\left(p^{\prime} \Delta \pi_{R}+(1-p)-p^{\prime} \Delta \pi_{L}\right)\right\}=0
\end{aligned}
$$

It follows that:

$$
\begin{aligned}
& \Delta \pi_{L}^{P I}=\frac{\alpha_{L} \Delta \theta-\frac{k \beta}{v}}{1-r \beta^{2}}+ \\
& \left.-\frac{p^{\prime}\left(\Delta \pi_{L}-\Delta \pi_{R}\right)}{1-p\left(\Delta \pi_{L}-\Delta \pi_{R}\right)}\left\{\frac{\alpha_{L} \Delta \theta-k \beta}{1-r \beta^{2}}\left(\Delta \pi_{L}-\Delta \pi_{R}\right)-\frac{1}{2}\left[\left(\Delta \pi_{L}\right)^{2}-\left(\Delta \pi_{R}\right)^{2}\right]\right\}+\right\} \\
& -\frac{(1-v)}{v\left(1-r \beta^{2}\right)} \cdot \frac{1}{1-p\left(\Delta \pi_{L}-\Delta \pi_{R}\right)} \cdot\left\{-k \beta p^{\prime}\left(\Delta \pi_{L}-\Delta \pi_{R}\right)-r \beta^{2}\left[p \Delta \pi_{R}+\right\}\right. \text { Electoral effect } \\
& \left.\left.+(1-p)\left(\Delta \pi_{L}\right)\right]\left(p^{\prime} \Delta \pi_{R}+(1-p)-p^{\prime} \Delta \pi_{L}\right)\right\}
\end{aligned}
$$


(14) and (16) represent a system of nonlinear differential equations. We solve this system numerically. The results of the simulations are shown in figures: (5) (6) (7) and (8) for different values of some parameters.

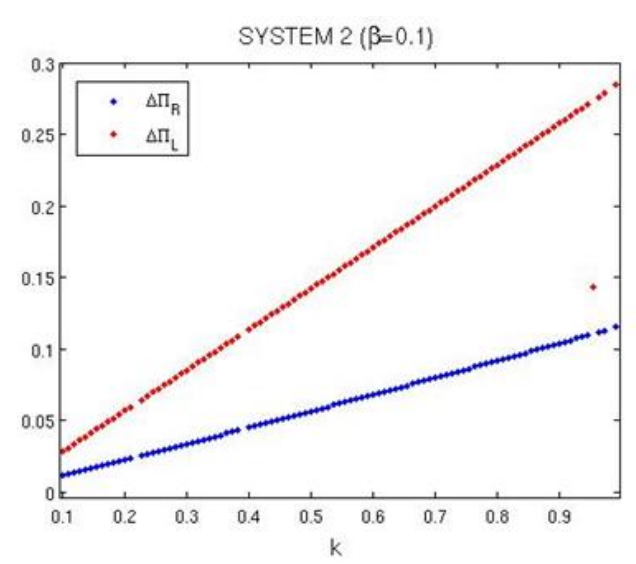

Figure 5.

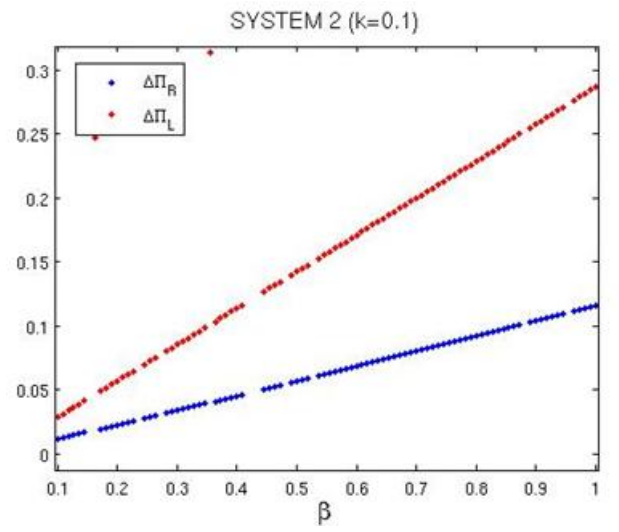

Figure 7.

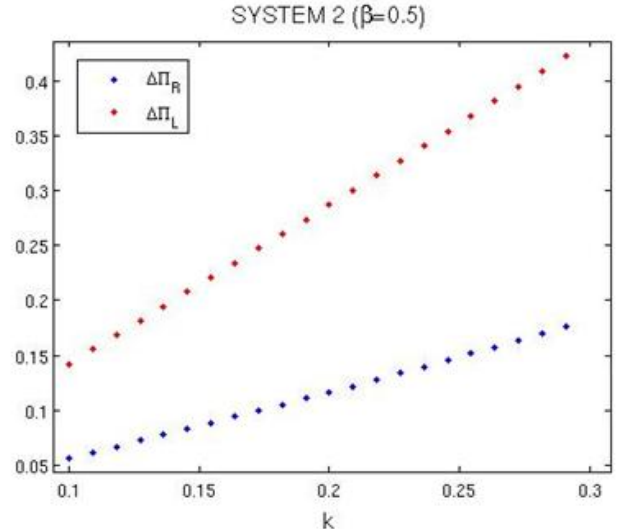

Figure 6.

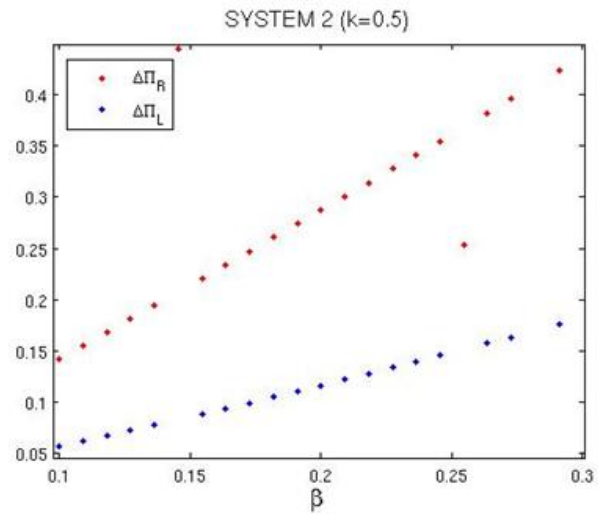

Figure 8 .

For both parties, the electoral effect still includes a term taking the same form as with a politically dependent Central Banker. However, there appears a new term which captures the impact of the choice of the platform on the agency cost of delegation to an independent Central Banker.

More importantly, the greater sensitivity of the swing voter to inflation variations $(\Delta \pi)$ under independence may increase the convergence of the platforms towards middle-road policies. This is clear on comparing the results of the system (1) (which is the institutional monetary regime under political dependence) with the results of the system (2) (which is the institutional monetary regime under political independence).

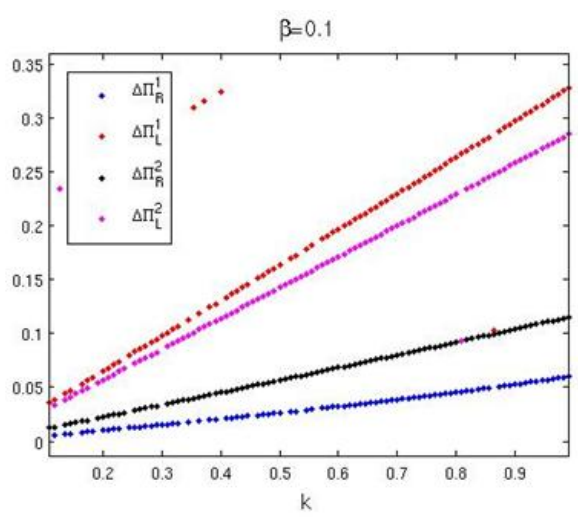

Figure 9.

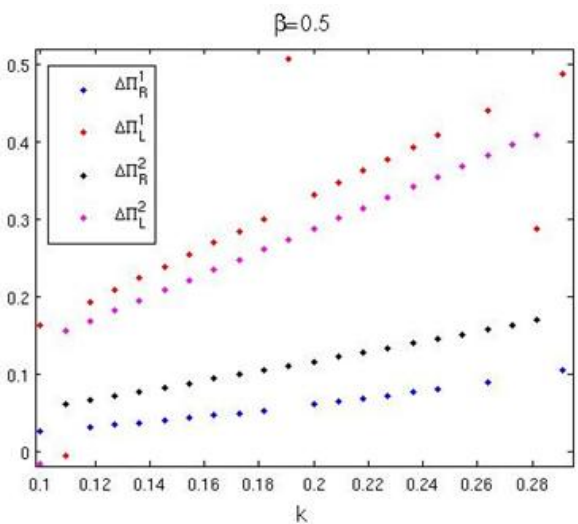

Figure 10. 


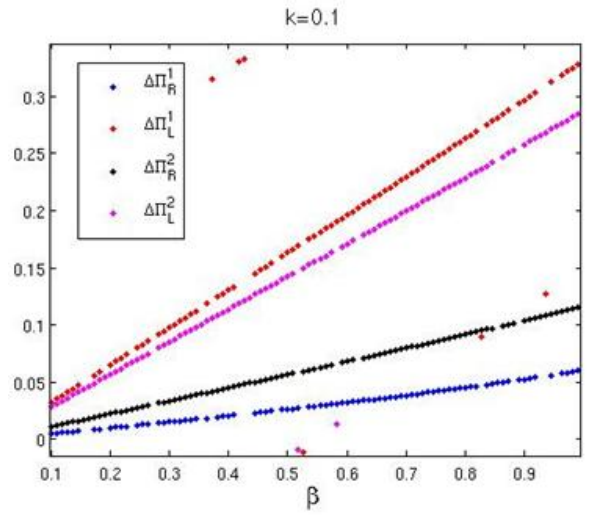

Figure 11.

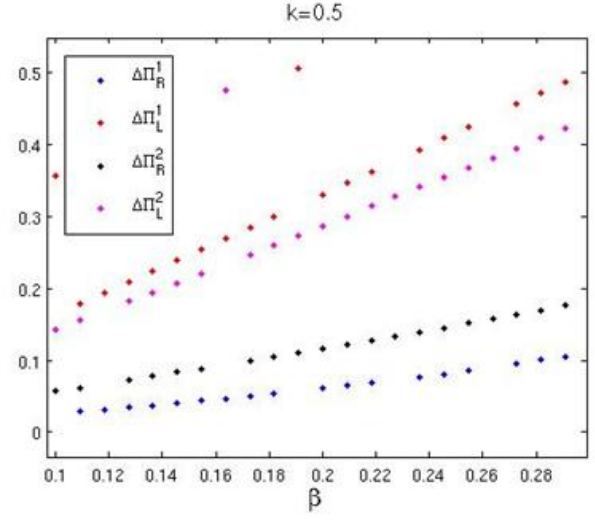

Figure 12.

This would reinforce Gabillon-Martimorts' finding that the independent Central Banker makes policies converge further one towards the order.

\section{Conclusions}

The foregoing analysis has examined the interesting feedback between institutions and election results. In this case, the amount of political uncertainty and the choice of institutional design have been determined simultaneously in the model. Endogenizing political uncertainty reinforces the stabilization effect. A rightist (resp. leftist) policymaker increases (resp. decreases) the variance of inflation and now looks much more like a leftist (resp. rightist) policy maker.

This finding strengthens the hypothesis that the independence of the $\mathrm{CB}$ is the best institutional design with which to protect the general interests of 'society'. In fact, a Central Banker independent from the political principal that appoints it represents the best control by the minority with respect to decisions taken by the elected political majority.

This line of research could continue in various directions. The first is consideration of political systems more complex than a two-party one: that is, multi-party systems and coalition governments, which are generally associated with parliamentary political regimes. The political economics literature (Note 20) emphasises, in fact, that these characteristics increase political uncertainty. This suggests that the benefits of the Central Bank's political independence are greater in parliamentary systems: an aspect which should be analysed both theoretically and empirically.

A second direction for further inquiry within the framework analysed is theoretical and empirical investigation of the possible separation of banking supervision from monetary policy. This should increase the transaction costs deriving from collusion between banks and monetary authorities.

\section{Acknowledgments}

I thank John Driffill, Steffen Huck, Kenjiro Hori, Joe Pearlman, Ourania Dimakou, Erika Uberti and participants at the European Public Choice Society conference in Jerusalem, for their many helpful comments and suggestions. A previous version of this paper circulated under the title "Political stabilization by an independent Central Bank".

\section{References}

Alesina, A. (1988). Credibility and Policy Convergence in a Two-party System with Rational Voters. American Economic Review, 78, 796-806.

Balke, N. (1990). The Rational Timing of Parliamentary Elections. Public Choice, 65, $201-216$. https://doi.org/10.1007/BF00204945

Barro, R., \& Gordon, D. (1983). Rules, Discretion and Reputation in a Model of Monetary Policy. Journal of Monetary Economics, 12, 101-122. https://doi.org/10.1016/0304-3932(83)90051-X

Canova, T. (2007). Non-state Actors and International Institutional Order: Central Bank Capture and the Globalization of Monetary Amnesia. American Society of International Law Annual Proceedings, 101, 8-16. https://doi.org/10.1017/S0272503700026422 
Chowdhury A. (1991). The Relationship Between the Inflation Rate and its Variability: The Issues Reconsidered. Applied Economics, 23, 993-1003. https://doi.org/10.1080/00036849100000001

Cukierman, A. (2013). Regulatory Reforms and the Independence of Central Banks and Financial Supervisors. SUERF Studies on States, Banks, and the Financing of the Economy, 3, 121-134.

Ellis C. (1991). Endogenous Voting in a Partisan Model with Rational Voters. Journal of Macroeconomics, 13, 267-278. https://doi.org/10.1016/0164-0704(91)90055-Y

Faure-Grimaud, A., \& Martimort, D. (2001). On some agency cost of delegated contracting. Economic Letter, 71, 75-82. https://doi.org/10.1016/S0165-1765(00)00398-0

Faure-Grimaud, A., \& Martimort, D. (2003). Regulatory Inertia. Rand Journal of Economics, 34, 413-437. https://doi.org/10.2307/1593739

Friedman M. (1977). Nobel Lecture: Inflation and Unemployment. Journal of Political Economy, 85, 451-472. https://doi.org/10.1086/260579

Fudenberg, D., \& Tirole, J. (1991). Game Theory. Cambridge(MA): MIT Press.

Gabillon, E., \& Martimort, D. (2004). The Benefits of Central Banks' Political Indipendence. European Economic Review, 48, 353-378. https://doi.org/10.1016/S0014-2921(02)00267-2

Kane, E. (1980). Politics and FED Policy-Making. Journal of Monetary Economics, 6, 199-211. https://doi.org/10.1016/0304-3932(80)90027-6

Laffont, J. J., \& Martimort, D. (1999). Separation of regulators against collusive behaviour. Rand Journal of Economics, 107, 1089-1127. https://doi.org/10.2307/2556079

Laffont, J. J., \& Tirole, J. (1993). A Theory of Incentives in Regulation and Procurement. Cambridge (MA): MIT Press.

Peek, J., Rosemgren, E., \& Tootell, G. (1999). Is Bank Supervision Central to Central Banking? Quarterly Journal of Economics, 114, 629-653. https://doi.org/10.1162/003355399556098

Persson, T., \& Tabellini G. (2003). The economic effects of constitutions. Cambridge (MA): MIT Press. https://doi.org/10.7551/mitpress/2591.001.0001

Persson, T., \& Tabellini, G. (2000). Political Economics. Explaining Economic Policy. Cambridge (MA): MIT Press.

Posen, A. (1995). Declaration Are Not Enough: Financial Sector Soucres of Central Bank Indipendence. Nber Macroeconomics Annual, 253-274. https://doi.org/10.1086/654279

Posner, R. (1974). Theory of Economic regulation. The Bell Journal of Economics and Management Science, 5 , 335-358. https://doi.org/ 10.2307/3003113

Stigler, G. (1971). The Theory of Economic Regulation. The Bell Journal of Economics and Management Science, 2, 3-21. https://doi.org/10.2307/3003160

Tirole, J. (1986). Hierarchies and bureaucracies: On the role of collusion in organizations. Journal of Law, Economics and Organization, 2, 181-214. https://doi.org/10.1093/oxfordjournals.jleo.a036907

Tirole, J. (1992). Collusion and the Theory of Organizations. In J. J. Laffont (Ed.), Advances in Economic Theory (Vol. 2, pp. 151-206). Cambridge: Cambridge University Press. https://doi.org/10.1017/CCOL0521430194.003

\section{Notes}

Note 1. Canova (2007, p. 3) discussed the non-state actors that impacted on the present global economic order by capturing state institutions - the regulated industry capturing the regulator - often with promises of future employment, political support, and campaign contributions. But he mentioned that there was a "relative silence regarding the capture of Central Banks, perhaps the most significant agency capture by non-state actors in today's de-jure international financial setup".

Note 2. On this see Posen (1995), who argues that the financial sector is generally the main supporter of the Central Bank's political independence.

Note 3. Kane (1980) argues that builders and construction unions also form an anti-inflationist group for similar reasons. 
Note 4. Of course, there have been moments in history - for example, the financial crisis of 2007 - when also the financial sector has found it convenient to ease its debts.

Note 5. This section follows the same notation used by Gabillon and Martimort (2004).

Note 6. The political principal can be conceived as the elected legislative or executive branch of the government.

Note 7. It is a contract between an elected political principal, a CB, and the private sector in a two-tier model of monetary policy.

Note 8. The Central Bank has no weight in the principal's objective function, capturing the fact that redistributing wealth to bureaucrats as such is not part of the government's objective. Alternatively, civil servants represent a group with negligible social weight. The main insights of the analysis are robust to the case where parties' objective functions give the same positive (but less than one) weight to the regulator's utility. (See Laffont and Martimort, 1999; Faure-Grimaud and Martimort, 2003, where they show that the separation of powers in regulation may act as a commitment against the threat of regulatory capture ). This means considering the objective function in this way: $S W_{\alpha i}=-\pi^{2} / 2+\alpha_{i} \theta\left(\pi-\pi^{e}\right)-\lambda s$, for any $0<\lambda<1$.

Note 9. The pro-inflationist interest group can be easily seen in the model. In this case the utility of this group is: $I G=\gamma \theta\left(\pi-\pi^{e}\right)$ with $\gamma>0$.

Note 10. A 'credible report' means that the CB presents documents produced by its research department showing that the economy is in a good or bad state.

Note 11. See Tirole (1992) for a first discussion of the origins of these transaction costs.

Note 12. Gabillon and Martimort (2004) assume that $\mathrm{K}($.) is strictly concave and increasing in the interval $(0, k / r)$. These two assumptions capture the fact that transferring more wealth to the CB makes it easier for the interest group to affect his decision-making but the marginal efficiency of doing so decreases.

Note 13. The difference in inflation targets under political control is: $\Delta \pi_{i}^{P C}=\frac{\alpha_{i} \Delta \theta-k \beta / v}{1-r \beta^{2} / v}$ with $i \in\{L, R\}$. The difference in inflation targets under political independence is: $\Delta \pi_{R}^{P I}=\frac{\alpha_{R} \Delta \theta-k \beta / v+(1-p)\left(r \beta^{2} / v\right) \Delta \theta \Delta \alpha}{1-r \beta^{2} / v}$ and $\Delta \pi_{L}^{P I}=\frac{\alpha_{L} \Delta \theta-k \beta / v-p\left(r \beta^{2} / v\right) \Delta \theta \Delta \alpha}{1-r \beta^{2} / v}$.

Note 14. A similar approach is considered by Alesina (1988), Balke (1988) and Ellis (1991).

Note 15. This depends on differences in the ideologies if voters are rightist or leftist.

Note 16. Even in the case of monetary policy offered when the central banker benefits from political independence, the SW function is the same; only the agency cost AC changes.

Note 17. In effect, an optimal monetary policy proposed by principal $i$ must implement collusion-proofness at minimal agency cost: $A C_{i}^{P C}\left(\Delta \pi_{i}\right)=\min _{\left\{\underline{s}_{i}, \bar{s}_{i}\right\}} v \underline{S}_{i}+(1-v) \overline{s_{i}}$ s.t. a collusion-proofness constraint and participation constraint. For the first constraint, the Central Banker must be sufficiently rewarded to report truthfully, so that colluding with the anti-inflationist interest group becomes a dominated strategy. The grand-contract must thus satisfy a collusion-proofness constraint: $\bar{S}_{i}-\underline{s}_{i} \geq K\left(\beta \Delta \pi_{i}\right)$. The left-hand side represents the wage differential necessary to prevent collusive behaviour and to induce a truthful announcement by the Central Banker. The right-hand side represents the benefits that the Central Banker can obtain from his collusive relationship with the anti-inflationist interest group. For the second constraint, the Central Banker prefers to enter the public sector rather than obtain a utility equal to zero, so that the participation constraint must be satisfied: $\underline{s}_{i} \geq 0$. Note that when $\Delta \pi_{i}=\bar{\pi}_{i}-\underline{\pi}>0$, the two constraints imply also $\bar{S}_{i}>0$. This last participation constraint can be omitted in what follows as long as the stake for collusion remains positive. For further details on collusion-proofness constraint and participation constraint see Gabillon and Martimort (2004, p. 364). 
Note 18. See note 13 to compare this results with those by Gabillon-Martimort.

Note 19. Gabillon and Martimort, in order to prevent collusion between interest groups and central bankers, consider an ex ante collusion-proofness constraint:

$$
p\left(\bar{s}_{R}-\underline{s}_{R}\right)+(1-p)\left(\bar{s}_{L}-\underline{s}_{L}\right) \geq K \beta\left[\left(p \Delta \pi_{R}\right)+(1-p) \Delta \pi_{L}\right]
$$

The left-hand side above represents the wages expected to prevent collusive behaviour; the right-hand side represents the bribe that the anti-inflation group is willing to pay to the Central Banker to make him lie in his announcement of the economic shock. The Central Banker strictly prefers to commit to a side-contract before political uncertainty resolves rather than wait for the outcome of the election. Indeed, because the efficiency of side-contracting $K($.$) is a strictly concave function of the collusive stake:$ $K \beta\left[\left(p \Delta \pi_{R}\right)+(1-p) \Delta \pi_{L}\right]>p K\left(\beta \Delta \pi_{R}\right)+(1-p) K\left(\beta \Delta \pi_{L}\right)$

The optimal monetary policy proposed by principal $i$ must implement collusion-proofness at minimal agency cost: $A C_{i}^{P I}\left(\Delta \pi_{i}\right)=\min _{\left\{s_{i}, \bar{s}_{i}\right\}} v \underline{s}_{i}+(1-v) \overline{s_{i}}$ s.t. a collusion-proofness constraint and participation constraint. The participation constraints are identical to the case of political dependence $\underline{s}_{i} \geq 0$, from which it follows that $\bar{s}_{i}>0$. For every detail on this point see Gabillon and Martimort, (2004, p.,368).

Note 20. See Persson and Tabellini (2000; 2003).

\section{Copyrights}

Copyright for this article is retained by the author(s), with first publication rights granted to the journal.

This is an open-access article distributed under the terms and conditions of the Creative Commons Attribution license (http://creativecommons.org/licenses/by/4.0/). 